\title{
PENINGKATAN KEPUASAN KERJA GURU DENGAN CARA PENGUATAN KEPEMIMPINAN TRANSFORMASIONAL DAN BUDAYA ORGANISASI
}

\author{
Siti Julaeha ${ }^{a)}$, M. Entang ${ }^{b}$, Herfina ${ }^{b *}$ \\ ${ }^{a)}$ SMAN 1 Citeureup, Bogor, Indonesia \\ ${ }^{b)}$ Universitas Pakuan, Bogor, Indonesia \\ *)e-mail korespondensi: herfina@unpak.ac.id
}

riwayat artikel : diterima: 18 Juni 2020; direvisi: 21 Juni 2020; disetujui: 06 Juli 2020

\begin{abstract}
Abstrak. Penelitian ini bertujuan untuk mengetahui secara empirik kepuasan kerja guru dengan cara penguatan kepemimpinan transformasional dan budaya organisasi guru honorer SMK Swasta se-Kecamatan Cibungbulang. Jumlah sampel penelitian sebanyak 158 guru yang diambil dengan menggunakan teknik proportional random sampling. Metode yang digunakan adalah metode korelasional. Pengujian hipotesis yang dilakukan dengan menggunakan analisis statistik parametrik dalam bentuk analisis regresi linier sederhana dan berganda, analisis korelasi sederhana dan berganda dengan taraf signifikansi $\alpha=0,01$ dan $\alpha=0,05$. Penelitian ini menghasilkan empat kesimpulan. Pertama, terdapat hubungan positif dan signifikan antara kepemimpinan transformasional dengan kepuasan kerja guru dengan koefisien korelasi $\mathrm{ry}_{1}=0,588$, koefisien determinasi $\mathrm{Ry}_{12}=0,3461$. Kedua, terdapat hubungan positif dan signifikan antara budaya organisasi dengan kepuasan kerja guru dengan koefisien korelasi ry ${ }_{2}=0,626$, koefisien determinasi $R y_{22}=$ 0,3914 . Ketiga, terdapat hubungan positif dan signifikan kepemimpinan transformasional dan budaya organisasi secara bersama-sama dengan kepuasan kerja guru dengan koefisien korelasi ry $_{12}=0,71$ dan koefisien determinasi $\mathrm{Ry} \cdot{ }_{122}=0,504$. Keempat kepuasan kerja guru dapat ditingkatkan dengan cara penguatan kepemimpinan transformasional dan budaya organisasi, baik secara sendiri-sendiri maupun bersama-sama terhadap kepuasan kerja. Penelitian ini menyimpulkan kepuasan kerja guru dapat ditingkatkan dengan cara penguatan kepemimpinan transformasional dan budaya organisasi.
\end{abstract}

Kata Kunci: kepuasan kerja guru; kepemimpinan transformasional; budaya organisasi

\section{IMPROVING TEACHER JOB SATISFACTION BY STRENGTHENING TRANSFORMATIONAL LEADERSHIP AND ORGANIZATIONAL CULTURE}

\begin{abstract}
This study is intended to empirically determining teacher job satisfaction by strengthening transformational leadership and organizational culture of honorary teachers of private vocational schools at Cibungbulang District. The number of research sample was 158 teachers taken using proportional random sampling techniques. The utilizing method was the correlational method. Hypothesis testing was carried out using parametric statistical analysis in the form of simple and multiple linear regression analysis, simple and multiple correlation analysis with significance levels $\alpha=0.01$ and $\alpha=0.05$. This research resulted in four conclusions. Firstly, there was a positive and significant relationship between transformational leadership and teacher job satisfaction where the correlation coefficient $\mathrm{ry}_{1}=0.588$, the coefficient of determination $\mathrm{Ry}_{12}=0.3461$. Secondly, there was a positive and significant relationship between organizational culture and teacher job satisfaction where the correlation coefficient $\mathrm{ry}_{2}=0.626$, the coefficient of determination $\mathrm{Ry}_{22}=0.3914$. Thirdly, there was a positive and significant relationship between both transformational leadership and organizational culture with teacher job satisfaction where the correlation coefficient ry. ${ }_{12}=0.71$ and the coefficient of determination $\mathrm{Ry}_{\cdot 122}=0.504$. Fourthly, the job satisfaction could be improved by strengthening transformational leadership and organizational culture, both separately or altogether. It can be concluded that teacher job satisfaction can be improved by strengthening transformational leadership and organizational culture.
\end{abstract}

Keywords: teacher job satisfaction; transformational leadership; organizational culture

\section{PENDAHULUAN}

Kepuasan kerja merupakan unsur yang berpengaruh terhadap kinerja yang mana jika kepuasan kerja belum optimal akan berdampak pada hasil kerja. Seorang guru yang memliki kepuasan kerja yang tinggi akan tampak pada perilaku yang positif dalam memfasilitasi peserta didik dalam belajar. Guru yang merasakan kepuasan dalam bekerja tentunya akan berupaya semaksimal mungkin untuk menyelesaikan tugas pekerjaannya, sehingga prestasi kerja dapat dicapai. Kepuasan kerja ditandai dengan munculnya rasa puas karena terselesaikannya tugas-tugas yang menjadi tanggung jawab guru tersebut secara tepat waktu, disamping itu munculnya dedikasi, kerajinan, ketekunan, inisiatif dan kreativitas kerja yang tinggi dalam bekerja. Munculnya lembaga pendidikan yang maju dan berkualitas tentu tidak lepas dari kerja semua elemen yang ada di dalamnya. Kepuasan kerja memungkinkan orang untuk mendedikasikan diri dalam seluruh pekerjaanya. Hal ini tentu akan memberi pengaruh yang besar dalam tercapainya tujuan pendidikan. Kepuasan kerja akan diwujudkan dalam bentuk kerja yang nyata dengan kemauan yang keras disertai tanggung jawab untuk mewujudkannya. Kepuasan kerja akan memberi peluang dan 
kesempatan, serta mendorong guru untuk bekerja atas dasar sistem nilai (values system) yang baik dan benar, sehingga bersedia, tanpa paksaan, berpartisipasi secara optimal dalam mencapai visi, misi dan tujuan sekolah. Guru yang mempunyai kepuasan kerja tinggi akan bekerja dengan semangat, sehingga memberikan peluang untuk mencapai hasil kerja yang tinggi. Kepuasan kerja guru terasa sangat penting, karena hal ini akan mendorong guru untuk tetap konsisten terhadap pekerjaannya. Kepuasan kerja akan memberi efek jangka panjang yang tampak dalam kinerja guru dan menjadi faktor penting dalam menentukan keberhasilan organisasi. Kepuasan kerja yang rendah dari guru bisa berdampak pada munculnya berbagai kecenderungan turnover guru, pelanggaran tata tertib, semangat kerja yang rendah, cepat merasa bosan, dan sering absen. Kepuasan kerja akan merunjuk pada proses membangun komitmen terhadap sasaran organisasi dan memperkuat kepercayaan pada usaha mencapai sasaran-sasaran yang ditetapkan. Kepuasan kerja ini pada akhirnya memotivasi guru untuk bekerja lebih semangat dan meningkatkan produktivitas sehingga akan mengarah pada terciptanya visi misi sekolah.

Fenomena ini juga terjadi di Sekolah SMK Swasta yang ada di Kecamatan Cibungbulang yang tampak belum optimal dari segi kepuasan kerja guru, hal dapat dilihat dari hasil survey menunjukan hasil bahwa terdapat 55\% guru masih banyak yang menerima gaji tidak sesuai dengan beban kerja dan waktu penerimaan gaji yang belum sesuai dengan jadwal yang ditetapkan. 53\% guru belum menunjukan relasi serta hubungan yang baik sesama rekan kerja sehingga cenderung individual, 59\% guru masih belum optimal mengembangkan potensi dirinya serta membantu peserta didik di luar jam kerja, 57\% guru merasa kondisi sekolah kurang aman serta nyaman dalam menjalani pekerjaannya, dan 58\% guru merasa tidak diberikan kesempatan yang sama didalam membangun serta mengembangkan karirnya. Berdasarkan dari latar belakang masalah tersebut diatas, perlu dilakukan penelitian untuk mengungkapkan masalah dan meningkatkan kepuasan kerja guru sebagai variabel utama yang dihubungkan dengan variabel lain yang diduga memiliki korelasi dengan kepemimpinan transpormasional kepala sekolah dan budaya organisasi

Kepuasan kerja (job satisfaction) adalah orientasi afektif (affective orientation) yang dimiliki karyawan terhadap pekerjaannya. Kepuasan kerja dengannya dapat dianggap sebagai perasaan keseluruhan tentang pekerjaan atau sebagai konstelasi sikap terkait berbagai aspek pekerjaan (Hoboubi et al, 2017:67-71) yang mana hal itu langsung tercermin dalam perilaku kerja karyawan pada pekerjaan yang digeluti (Wen, Gu, and Wen 2018:1-27). Kepuasan kerja adalah sikap dan perasaan guru terhadap pekerjaannya terkait dengan situasi kerja, imbalan/gaji, hubungandengan atasan, kerjasama antar personal dan hal-hal lain yang menyangkut fisik dan psikologis (Suchyadi, Karmila, \& Safitri, 2019). Kepuasan kerja dilihat juga sebagai salah satu dari beberapa mekanisme individu yang secara langsung mempengaruhi kinerja dan komitmen organisasi (Colquitt, Lepine, and Wesson 2017:96-125), sebagai kenyataan sejauh mana seseorang menyukai atau tidak menyukai pekerjaan mereka (Ferreira, 2019:1-36) yang mana secara langsung terkait dengan motivasi (motivation), kinerja (performance), absensi (absenteeism), dan pergantian (turnover) karyawan (Jung and Suh,2019:1-12). Salah satu faktor yang mendukung guru untuk bekerja dengan sebaik-baiknya adalah kepuasan kerja. Artinya jika guru puas dengan pekerjaannya maka mereka akan bekerja dengan penuh semangat dan bertanggung jawab (Suchyadi, Karmila, Nurlela, et al., 2019). Wen, Gu, dan Wen (2018:1-27) dalam mengukur kepuasan kerja karyawan, yang dapat menggambarkan perasaan karyawan terhadap keseluruhan pekerjaan mereka menggunakan beberapa indikator seperti; work characteristic yang menggambarkan tingkat kepuasan karyawan dengan pekerjaan secara keseluruhan, peluang pengembangan karir, stabilitas keamanan kerja pada jangka waktu dekat, menengah, dan panjang

(Hoboubi et al,2017:67-71); organizational environment yang mendeskripsikan lingkungan kantor yang baik dan peralatan kerja bisnis yang lengkap, organizational management seperti eksistensi kepemimpinan yang kuat, job involvement yang mewakili aspek perasaan pribadi yang mana karyawan merasa diperkaya akan kehidupan kerja yang digeluti, organizational commitment yang mendeskripsikan disposisi karyawan dengan organisasi yang terwujud dalam rasa bangga dengan organisasi, dan job value yang mewakili aspek keefektifan menyelesaikan masalah dalam pekerjaan. Ferreira dan Susana (2019:1-36) menggunakan beberapa indikator lain yang dipakai untuk mengukur kepuasan kerja seperti; karakteristik individu (individual characteristics), ketentuan kontrak (contract conditions), karakteristik pekerjaan atau organisasi (job/organizational characteristics), faktor ekonomi makro (macroeconomic factors), dan kondisi lingkungan tempat kerja (workplace environmental conditions.). Dari beberapa teori di atas dapat disintesiskan bahwa kepuasa kerja adalah perasaan yang dimiliki karyawan terhadap pekerjaannya yang tercermin dalam perilaku kerja, dengan indikator pengukurannya berupa; 1) Salary (gaji), 2) Co-workers (rekan kerja), 3) Job characteristic (karaktristik pekerjaan), 4) Workplace Environmental Conditions (kondisi lingkungan kerja), dan 5) Career Opportunities (kesempatan berkarir).

Kepemimpinan transformasional mengacu pada kemampuan pemimpin organisasi untuk mempengaruhi perilaku dan kepentingan pribadi pengikut terhadap tujuan organisasi (Liu and Lee 2018:1-10), yang mana seorang pemimpin mengubah norma-norma dan nilai- nilai bawahan dan memotivasi mereka untuk mencapai tujuan organisasi (Wang et al. 2017:1-36) dan menekankan pertukaran kreatif antara pemimpin dan pengikut untuk mendorong perubahan pada pengikut yang didorong oleh visi organisasi (Deinert et al. 2015:1-26). Pemimpin transformasional menghasilkan perubahan pada pengikut dengan adanya dorongan untuk melampaui kepentingan pribadi dan mendorong cara berpikir karyawan untuk mengedepankan tujuan organisasi (Amor, Vazquez, and Faína 2019:1-10). Kepemimpinan transformasional digambarkan sebagai gaya kepemimpinan yang berfokus pada mengubah, menginspirasi, mendorong, dan memimpin dengan memberi contoh sambil juga mengembangkan potensi pengikut (Kammerhoff, Lauenstein, and Schütz 2018:1-36). Dengan merujuk pada definisi ini maka beberapa indikator seperti memberikan pengaruh ideal (atribut), pengaruh ideal (perilaku), motivasi inspirasional, stimulasi 
intelektual, dan pertimbangan individual, menjadi kekuatan seorang pemimpin transformasional (Liu and Lee 2018:1-10). Seorang pemimpin transformasional menurut Schaubroeck, Lam, and Peng (2016:45-58) adalah pribadi yang memiliki visi yang jelas, mampu menginspirasi anggota, memberikan model yang baik, mendorong karyawan untuk menjadi team players, kreatif, dan inovatif. Dari beberapa teori di atas maka dapat disintesiskan Kepemimpinan transformasional (transformational leadership) adalah gaya kepemimpinan dengan cara mempengaruhi sikap dan perilaku anggota dengan menginspirasi, mendorong, memberi contoh, dan memotivasi untuk mencapai tujuan organisasi dengan melampaui kepentingan pribadi, dengan indikator pengukurannya berupa; 1) Kharismatik (idealized influence), 2) motivasi inspirasi (inspirational motivation), 3) stimulasi intelektual (intellectual stimulation), 4) dukungan individual (individualized concideration), 5) visi (articulating a vision)

Dai, Chan, and Yee (2018:227-236) Budaya organisasi (organizational culture) mengacu pada sistem nilai, kepercayaan (beliefs), dan perilaku (behavior) di antara karyawan di semua tingkatan dan menampilkan sifat-sifat organisasi dengan seperangkat karakteristik bersama yang unik, termasuk asumsi, kepercayaan, norma, dan ide, yang mencerminkan tujuan dan praktik organisasi. Budaya organisasi juga dideskripsikan dengan mengacu pada nilai-nilai dan kepercayaan umum yang dimiliki bersama oleh individu dalam organisasi yang mengindikasikan beberapa aspek yang mengacu pada nilai bersama ini seperti keterlibatan (involvement) yang menggambarkan tingkat partisipasi dalam organisasi, konsistensi (consistency) yakni sistem kontrol implisit yang berdasar pada nilai-nilai internal organisasi, (adaptability) yaitu kemampuan beradaptasi dan kapasitas untuk melakukan perubahan internal dalam menanggapi kondisi eksternal, dan adanya misi (mission) yang memberikan tujuan dan makna serta visi jangka panjang dari organisasi (Dasgupta and Gupta, 2019:1-35) dan (Iljins, Skvarciany, and Gaile-Sarkane 2015:44-50).

Upadhaya (2018:108-122) mendefinisikan budaya organisasi lebih sebagai sistem kontrol sosial berdasarkan norma dan nilai-nilai bersama (a social control system based on shared norms and values) yang menetapkan harapan tentang sikap dan perilaku yang sesuai untuk anggota kelompok dengan dua indikator umum yang tentunya mengikat seluruh anggota organisasi adalah keterarahan pada inovasi (innovation) dan sikap menghormati orang (respect for people) (Upadhaya et al, 2018:108122). Dai, Chan, and Yee (2018:227-236) melihat adanya hubungan budaya organisasi dengan kinerja organisasi yang dapat menghasilkan keunggulan kompetitif berkelanjutan. Budaya organisasi merupakan suatu sistem pemaknaan nilai bersama yang berfungsi untuk menciptakan perbedaan yang jelas antara satu organisasi dengan organisasi lainnya, dan memfasilitasi munculnya komitmen serta nilai-nilai dominan yang memiliki ciri utama (Suchyadi, 2017). Dari beberapa teori di atas maka dapat disintesiskan budaya organisasi (organizational culture) adalah seperangkat karakteristik bersama seperti sistem nilai, kepercayaan, dan perilaku di antara karyawan yang mencerminkan tujuan organisasi, dengan indikator pengukurannya berupa: 1) sikap adaptif (adaptive), 2) hirarki (hierarchy), 3) dukungan (supportive), 4) kerja tim (teamwork), dan 5) inovasi (innovative).

\section{METODE PENELITIAN}

Penelitian ini bertujuan untuk melihat peningkatan kepuasan kerja guru. Penelitian ini merupakan penelitian kuantitatif dengan menggunakan metode survei dengan teknik korelasional dan SITOREM (Scientific Identification Theory to Conduct Operation Research in Education Management) (Hardhienata, 2017), dengan variabel terikat yaitu kepuasan kerja (Y) dan 2 variabel bebas yaitu kepemimpinan transformasional (X1) dan budaya organisasi (X2). Penelitian ini menggunakan 158 sampel guru honorer SMK Swasta se-Kecamatan

Cibungbulang Kabupaten Bogor yang ditentukan dengan menggunakan teknik proportional random sampling. Data dikumpulkan dengan menggunakan instrument kuesioner yang terdiri atas 1) kuesioner kepuasan kerja guru, terdiri atas 31 butir pernyataan yang diisi oleh guru, dengan 5 indikator pengukuran berupa; gaji, rekan kerja, karaktristik pekerjaan, kondisi lingkungan kerja, dan kesempatan berkarir. 2) Kuesioner kepemimpinan transformasional, terdiri atas 32 butir pernyataan yang diisi oleh guru, dengan 5 indikator pengukuran berupa; Kharismatik, motivasi inspirasi, stimulasi intelektual, dukungan individual, visi. 3) Kuesioner budaya organisasi, terdiri atas 33 butir pernyataan yang diisi oleh guru dengan 5 indikator pengukuran berupa; sikap adaptif, hirarki, dukungan, kerja tim, dan inovasi. Tingkat reliabilitas instrument kepuasan kerja guru adalah 0,88, kepemimpinan transformasional 0,96, dan budaya organisasi adalah 0,91, dengan menggunakan skala 1-5 (sangat baik) untuk pernyataan positif dan 5-1 (sangat baik) untuk pernyataan negatif pada semua instrumen. Sedangkan analisis SITOREM digunakan untuk mendidentifikasi, menganalisa, menilai dan menetapkan prioritas terhadap indikator variabel penelitian yang perlu untuk segera diperbaiki atau tetap dipertahankan dengan melakukan expert judgment pada aspek cost, benefit, urgency, dan importance setiap indikator (Hardheinata, 2017).

\section{HASIL DAN PEMBAHASAN}

\section{Hubungan Kepemimpinan Transformasional $\left(\mathrm{X}_{1}\right)$ dengan Kepuasan Kerja $(\mathrm{Y})$}

Berdasarkan hasil perhitungan analisis regresi linier sederhana dan analisis korelasi sederhana, maka didapatkan bahwa hubungan antara variabel kepemimpinan transformasional $\left(\mathrm{X}_{1}\right)$ dengan kepuasan kerja $(\mathrm{Y})$ guru honorer SMK Swasta 
Sekecamatan Cibungbulang Kabupaten Bogor, dapat dinyatakan dalam bentuk persamaan garis lurus $\hat{\mathrm{Y}}=68,481+0,459 \mathrm{X}_{1}$. Hal ini berarti bahwa setiap kenaikan satu unit kepemimpinan transformasional akan menaikkan 0,459-unit kepuasan kerja. Selain itu persamaan garis lurus ini juga menyatakan bahwa tanpa kehadiran variabel kepemimpinan transformasional $(\mathrm{X} 1=0)$ guru honorer SMK Swasta Sekecamatan Cibungbulang Kabupaten Bogor telah memiliki Kepuasan Kerja sebesar 68,481 unit. Hasil uji F pada analisis regresi linear sederhana memperlihatkan hubungan yang signifikan kedua variabel ini. Hal ini mengindikasikan bahwa, adanya pengaruh kepemimpinan transformasional terhadap kepuasan kerja guru honorer SMK Swasta Sekecamatan Cibungbulang Kabupaten Bogor. Sedangkan koefisien korelasi hubungan antara kepemimpinan transformasional (X1) dengan kepuasan kerja (Y) termasuk dalam kekuatan hubungan yang moderate $(r y 1=0,588)$ dengan tingkat signifikansi sebesar 11,24 (sangat signifikan). Dengan demikian hasil penelitian ini menunjukkan bahwa terdapat hubungan positif yang signifikan dengan kekuatan hubungan yang moderate antara variabel kepemimpinan transformasional (X1) dengan kepuasan kerja (Y). Perhitungan koefisien determinasi menunjukkan variabel kepemimpinan transformasional memberikan kontribusi 34,61\% terhadap kenaikan variabel Kepuasan Kerja (Y). Sedangkan 65,39\% disumbangkan oleh faktor lainnya seperti mutu peserta didik, kecerdasan emosional guru, budaya sekolah, peran kepala sekolah, dan motivasi mengajar. Penelitian ini mendukung penelitian terdahulu yang dilakukan oleh Munir, Rahman, Ariff. Malik, dan Hairunnisa (2012:885-890) dengan judul "Relationship between Transformational Leadership and Employees Job Satification among the Academic Staff." Penelitian tersebut menghasilkan temuan yaitu koefisien korelasi antara Transformational Leadership (kepemimpinan transformasional) dan Job Satification (kepuasan kerja) mencapai $\mathrm{r}=0,725(\mathrm{p}<0.00)$ yang berati bahwa terdapat hubungan yang sangat kuat antara Transformational Leadership (kepemimpinan transformasional) dan Job Satification (kepuasan kerja). Meskipun hasil koefisien korelasi pada penelitian-penelitian ini berbeda, namun semuanya memberikan kesimpulan yang sama yaitu bahwa terdapat hubungan positif yang signifikan antara Kepemimpinan Transformasional dengan Kepuasan Kerja.

\section{Hubungan antara Budaya Organisasi (X2) dengan Kepuasan Kerja (Y)}

Berdasarkan hasil perhitungan analisis regresi linier sederhana dan analisis korelasi sederhana, maka didapatkan bahwa hubungan antara variabel Budaya Organisasi (X2) dengan Kepuasan Kerja (Y) guru honorer SMK Swasta Sekecamatan Cibungbulang Kabupaten Bogor, dapat dinyatakan dalam bentuk persamaan garis lurus $\hat{\mathrm{Y}}=61,24+0,4809 \mathrm{X}_{2}$. Hal ini berarti bahwa setiap kenaikan satu unit Budaya Organisasi akan menaikkan 0,4809-unit Kepuasan Kerja. Selain itu persamaan garis lurus ini juga menyatakan bahwa tanpa kehadiran variabel Budaya Organisasi $(\mathrm{X} 2=0)$, guru honorer SMK Swasta Sekecamatan Cibungbulang Kabupaten Bogor telah memiliki Kepuasan Kerja sebesar 61,24 unit. Hasil uji F pada analisis regresi linear sederhana memperlihatkan hubungan yang signifikan kedua variabel ini. Hal ini mengindikasikan bahwa, adanya pengaruh Budaya Organisasi terhadap Kepuasan Kerja guru honorer SMK Swasta Sekecamatan Cibungbulang Kabupaten Bogor. Sedangkan koefisien korelasi hubungan antara Budaya Organisasi (X2) dengan Kepuasan Kerja (Y) termasuk dalam kekuatan hubungan yang moderate (ry2 $=0,626$ ) dengan tingkat signifikansi sebesar 12,84 (sangat signifikan). Dengan demikian hasil penelitian ini menunjukkan bahwa terdapat hubungan positif yang signifikan dengan kekuatan hubungan yang moderate antara variabel Budaya Organisasi dengan Kepuasan Kerja. Perhitungan koefisien determinasi menunjukkan variabel Budaya Organisasi memberikan kontribusi sebesar 39,14\% terhadap kenaikan variabel Kepuasan Kerja (Y). Sedangkan 60,86\% disumbangkan oleh faktor lainnya seperti mutu peserta didik, kecerdasan emosional guru, budaya sekolah, peran kepala sekolah, dan motivasi mengajar, efikasi diri. Penelitian ini mendukung penelitian terdahulu yang dilakukan oleh Davoodalmousavi (2013:389-399) dengan judul "The correlation between Organizational Culture and Job Satisfcction of employees in Biotechnology Production Companies." Penelitian tersebut menghasilkan temuan yaitu koefisien korelasi antara Organizational Culture (Budaya Organisasi) dan Job Satification (Kepuasan Kerja) mencapai $\quad \mathrm{r}=0,599$ ( $\mathrm{p}<0.00$ ) yang berati bahwa terdapat hubungan yang kuat antara Organizational Culture (Budaya Organisasi) dan Job Satification (Kepuasan Kerja). Hasil koefisien korelasi dalam penelitian relevan di atas berbeda dengan hasil koefisien korelasi pada penelitian ini $($ ry $1=$ 0,588). Meskipun hasil koefisien korelasi pada penelitian-penelitian ini berbeda, namun semuanya memberikan kesimpulan yang sama yaitu bahwa terdapat hubungan positif yang signifikan antara Budaya Organisasi dengan Kepuasan Kerja.

\section{Hubungan antara variabel Kepemimpinan Transformasional (X1) dan Budaya Organisasi (X2) Secara Bersama- Sama dengan Variabel Kepuasan Kerja (Y)}

Berdasarkan hasil perhitungan analisis regresi linier sederhana dan analisis korelasi ganda, maka didapatkan bahwa hubungan antara variabel Kepemimpinan Transformasional (X1) dan Budaya Organisasi (X2) Secara Bersama-Sama dengan Variabel Kepuasan Kerja (Y) guru honorer SMK Swasta Sekecamatan Cibungbulang Kabupaten Bogor, dapat dinyatakan dalam bentuk persamaan garis lurus, yakni $\hat{Y}=42,19+0,296 \mathrm{X} 1+0,345 \mathrm{X} 2$. Hal ini berarti bahwa setiap kenaikan satu unit Kepemimpinan Transformasional (X1) dan Budaya Organisasi (X2) secara bersama-sama akan menaikkan 0, 63-unit Kepuasan Kerja. Selain itu persamaan garis lurus ini juga menyatakan bahwa tanpa kehadiran variabel Kepemimpinan Transformasional dan Budaya Organisasi $(\mathrm{X} 1$ dan X2=0) secara bersama-sama, guru honorer SMK Swasta Sekecamatan Cibungbulang Kabupaten Bogor telah memiliki kepuasan kerja sebesar 42,19 unit. Hasil uji F pada analisis regresi linear berganda memperlihatkan hubungan yang signifikan kedua variabel ini. Hal ini mengindikasikan bahwa, adanya pengaruh Kepemimpinan Transformasional (X1) dan Budaya Organisasi (X2) Secara Bersama-Sama dengan Variabel Kepuasan Kerja (Y) guru honorer SMK Swasta Sekecamatan Cibungbulang Kabupaten Bogor. Sedangkan koefisien korelasi hubungan antara Kepemimpinan Transformasional (X1) dan Budaya Organisasi (X2) Secara 
Bersama-Sama dengan Variabel Kepuasan Kerja $(Y)$ termasuk dalam kekuatan hubungan yang tinggi $(r y .12=0,71)$ dengan tingkat signifikansi sebesar 19,37 (sangat signifikan). Dengan demikian hasil penelitian ini menunjukkan bahwa terdapat hubungan positif yang signifikan dengan kekuatan hubungan yang tinggi antara variabel Kepemimpinan Transformasional (X1) dan Budaya Organisasi (X2) Secara Bersama-Sama dengan Variabel Kepuasan Kerja (Y). Perhitungan koefisien determinasi (r2y.12 sebesar 0,54) menunjukkan yang artinya variabel Kepemimpinan Transformasional (X1) dan Budaya Organisasi (X2) memberikan sumbangan sebesar 50,4\% terhadap kenaikan variabel Kepuasan Kerja (Y). Sedangkan 49,6\% lainnya disumbangkan oleh faktor lainnya yang tidak diteliti dalam penelitian ini, seperti mutu peserta didik, kecerdasan emosional guru, budaya sekolah, peran kepala sekolah, motivasi mengajar, dan efikasi diri. Berdasarkan pembahasan hasil penelitian di atas, dapat disimpulkan bahwa terdapat hubungan positif yang signifikan dengan kekuatan hubungan yang kuat antara variabel Kepemimpinan Transformasional (X1) dan Budaya Organisasi (X2) Secara Bersama-Sama dengan Variabel Kepuasan Kerja (Y), yang bermakna semakin tinggi Kepemimpinan Transformasional (X1) dan Budaya Organisasi (X2) Secara Bersama-Sama, maka semakin tinggi pula Kepuasan Kerja yang diperlihatkan guru guru honorer SMK Swasta Sekecamatan Cibungbulang Kabupaten Bogor.

\section{SIMPULAN}

Penelitian ini menghasilkan empat kesimpulan. Pertama, terdapat hubungan positif dan signifikan antara kepemimpinan transformasional dengan kepuasan kerja guru dengan koefisien korelasi ry1=0,588, koefisien determinasi Ry12=0,3461. Kedua, terdapat hubungan positif dan signifikan antara budaya organisasi dengan kepuasan kerja guru dengan koefisien korelasi ry $2=0,626$, koefisien determinasi Ry22 $=0,3914$. Ketiga, terdapat hubungan positif dan signifikan kepemimpinan transformasional dan budaya organisasi secara bersama-sama dengan kepuasan kerja guru dengan koefisien korelasi ry.12=0,71 dan koefisien determinasi Ry.122=0,504. Keempat kepuasan kerja guru dapat ditingkatkan dengan cara penguatan kepemimpinan transformasional dan budaya organisasi, baik secara sendiri-sendiri maupun bersama-sama terhadap kepuasan kerja. Penelitian ini menyimpulkan kepuasan kerja guru dapat ditingkatkan dengan cara penguatan kepemimpinan transformasional dan budaya organisasi.

\section{REFERENSI}

Amor, A. M., Vazquez, J. P. A., \& Faína, J. A. (2019). Transformational leadership and work engagement : Exploring the mediating role of structural empowerment. European Management Journal,. https://doi.org/10.1016/j.emj.2019.06.007.

Colquitt, J. A., Lepine, J. A., \& Wesson, M. J. (2017). Organizational: Improving Performance and Commitment in the Workplace (Fifth Edit, Vol. 4). https://doi.org/10.1002/pdh.22

Dai, J., Chan, H. K., \& Yee, R. W. Y. (2018). Examining moderating effect of organizational culture on the relationship between market pressure and corporate environmental strategy. Industrial Marketing Management, 74(June 2017), 227236. https://doi.org/10.1016/j.indmarman.2018.05.003

Dasgupta, S., \& Gupta, B. (2019). Espoused cultural values as antecedents of internet technology adoption in an emerging economy. Information and Management. https://doi.org/10.1016/j.im.2019.01.004

Deinert, A., Homan, A. C., Boer, D., Voelpel, S. C., \& Gutermann, D. (2015). Transformational leadership sub-dimensions and their link to leaders ' personality and performance. The Leadership Quarterly.

Ferreira, S. (2019). Do Better Workplace Environmental Conditions improve Job. Journal of Cleaner Production. https://doi.org/10.1016/j.jclepro.2019.02.138

Hardhienata, S. (2017). The Development of Scientific Identification Theory to Conduct Operation Research in Education Management. IOP Conference Series: Materials Science and Engineering, 166.

Hoboubi, N., Choobineh, A., Ghanavati, F. K., Keshavarzi, S., \& Hosseini, A. A. (2017). The Impact of Job Stress and Job Satisfaction on Workforce Productivity in an Iranian Petrochemical Industry. Safety and Health at Work, 8(1), 67-71. https://doi.org/10.1016/j.shaw.2016.07.002

Iljins, J., Skvarciany, V., \& Gaile-Sarkane, E. (2015). Impact of Organizational Culture on Organizational Climate During the Process of Change. Procedia - Social and Behavioral Sciences, 213, 944-950. https://doi.org/10.1016/j.sbspro.2015.11.509

Jung, Y., \& Suh, Y. (2019). Mining the voice of employees : A text mining approach to identifying and analyzing job satisfaction factors from online employee reviews. Decision Support Systems, 123(June), 113074. https://doi.org/10.1016/j.dss.2019.113074

Kammerhoff, J., Lauenstein, O., \& Schütz, A. (2018). Leading toward harmony - Different types of conflict mediate how followers' perceptions of transformational leadership are related to job satisfaction and performance. European Management Journal. https://doi.org/10.1016/j.emj.2018.06.003

Liu, C. S., \& Lee, T. (2018). International Journal of Hospitality Management The multilevel e ff ects of transformational leadership on entrepreneurial orientation and service innovation. International Journal of Hospitality Management, 
(September), 0-1. https://doi.org/10.1016/j.ijhm.2018.10.006

Schaubroeck, J. M., Lam, S. S. K., \& Peng, A. C. (2016). Organizational Behavior and Human Decision Processes Can peers ' ethical and transformational leadership improve coworkers' service quality ? A latent growth analysis. Organizational Behavior and Human Decision Processes, 133, 45-58. https://doi.org/10.1016/j.obhdp.2016.02.002 comparison of British. The Social Science Journal. https://doi.org/10.1016/j.soscij.2017.07.011

Suchyadi, Y. (2017). Relationship between Work Motivation and Organizational Culture in Enhancing Professional Attitudes of Pakuan University Lecturers. Journal Of Humanities And Social Studies, 01(01).

Suchyadi, Y., Karmila, N., Nurlela, N., Mirawati, M., Purnamasari, R., Sri Indriani, R., ... Syahiril Anwar, W. (2019). Increasing Personality Competence Of Primary School Teachers, Through Education Supervision Activities In Bogor City. Journal Of Community Engagement (JCE), 01(01).

Suchyadi, Y., Karmila, N., \& Safitri, N. (2019). Kepuasan Kerja Guru Ditinjau Dari Peran Supervisi Kepala Sekolah Dasar Negeri Di Kecamatan Bogor Utara. Jurnal Pendidikan Dan Pengajaran Guru Sekolah Dasar (JPPGuseda), 02, 91-94. Retrieved from http://journal.unpak.ac.id/index.php/jppguseda

Upadhaya, B., Munir, R., Blount, Y., \& Su, S. (2018). Does organizational culture mediate the CSR - strategy relationship? Evidence from a developing country, Nepal. Journal of Business Research, 91(January 2016), 108-122. https://doi.org/10.1016/j.jbusres.2018.05.042

Wang, H., Demerouti, E., Blanc, P. Le, \& Wang, H. (2017). Transformational leadership, adaptability, and job crafting: The moderating role of organizational identification. Journal of Vocational Behavior. https://doi.org/10.1016/j.jvb.2017.03.009

Wen, X., Gu, L., \& Wen, S. (2018). Job satisfaction and job engagement: Empirical evidence from food safety regulators in Guangdong, China. Journal of Cleaner Production. https://doi.org/10.1016/j.jclepro.2018.10.089 